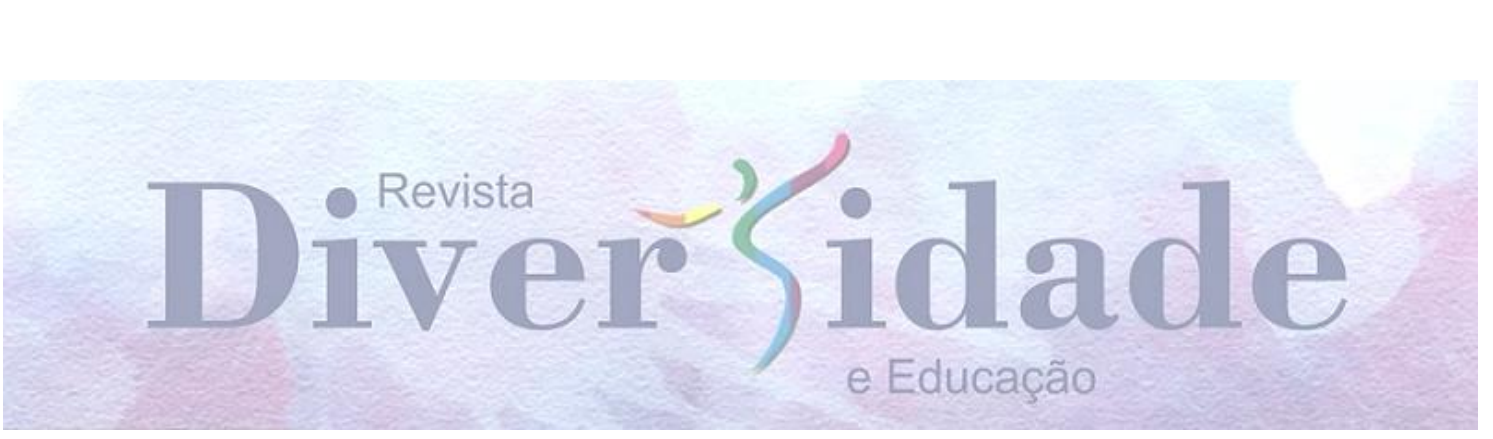

\title{
GÊNERO E SEXUALIDADE NAS REDES VIVENCIADAS NO COTIDIANO DAS ESCOLAS
}

\author{
GÉNERO Y SEXUALIDAD EN LAS REDES VIVENCIAS \\ EN EL COTIDIANO DE LAS ESCUELAS
}

\section{GENDER AND SEXUALITY IN THE NETWORKS EXPERIENCED IN THE DAILY LIFE OF SCHOOLS}

\author{
Patrick dos Santos Silva 1 \\ Heloísa Raimunda Herneck2 \\ Apolônia de J. Ferreira Silva 3
}

\section{RESUMO}

No ambiente escolar, os/as educandos/as protagonizam dimensões da sexualidade em conversas, nos namoros, nos bilhetes trocados. Na tentativa de desenvolver uma sexualidade saudável e sem preconceitos, foi desenvolvido na Escola Estadual Effie Rolfs o projeto de pesquisa: "Gênero e sexualidade nas redes vivenciadas pelos/as professores/as no cotidiano das escolas". O trabalho buscou acompanhar os fluxos das escolas e os processos de subjetivação implícitos nas produções dos/das professores/as no que se refere ao gênero e sexualidade. Inspirada na pesquisa cartográfica no/dos/com os cotidianos, sugerimos oportunizar outras formas de ver, pensar e compreender a temática. Nesse sentido, nos interessamos por acompanhar como as experiências vivenciadas nesses ambientes são reinventadas pelos/as professores/as ressignificando a sua formação.

Palavras- chave: Gênero. Sexualidade. Cotidianos Escolares.

\section{RESUMEN}

En el ambiente escolar, educandos protagonizan dimensiones de la sexualidad en conversaciones, en los enamorados, en los billetes. Em intento de desarrollar una sexualidad sana y sin prejuicios, se desarrolló en el Escuela Pública Effie Rolfs el proyecto de investigación: "Género y sexualidad en las redes vivenciadas por professores en el cotidiano de las escuelas". El trabajo buscó acompañar los flujos de las escuelas y los procesos de subjetivación implícitos en las producciones de los

1. Mestrando em Educação. Universidade Federal de Viçosa/ Minas Gerais/Brasil.

2 Doutora em Educação. Professora na Universidade Federal de Viçosa/ Minas Gerais/Brasil.

3 Doutoranda em Educação. Universidade Federal de Juiz de Fora/ Minas Gerais/Brasil. 
profesores en lo que se refiere al género y sexualidad. Inspirada en la investigación cartográfica en el / los / los cotidianos, sugerimos oportunizar otras formas de ver y comprender la temática. En sentido, nos interesamos por acompañar las experiencias vivenciadas en esos ambientes son reinventadas por los profesores a resignificando su formación.

Palabras clave: Género. Sexualidad. Cotidianos Escolares.

\section{ABSTRACT}

In the school environment the students take on the dimensions of sexuality in this conversations in the classroom, in the datings, in the little notes. In an attempt develop a healthy and unprejudiced sexuality, the research project "Gender and sexuality in the networks experienced by teachers in the daily life of schools" was developed in Public School Effie Rolfs. The work sought to monitor the flows of schools and the processes of subjectivation implicit in the productions of teachers concernig to gender and sexuality. Based on cartographic research in/of/with the day-to-day, we suggest providing other ways of seeing, thinking and understanding the theme. In this sense, we are interested in analyzing how the experiences experienced in these environments are reinvented by the teachers re-signifying their formation.

KEYWORDS: Gender. Sexuality. Daily lifes.

$$
* * *
$$

\section{Introdução}

No presente artigo busca-se apresentar os resultados finais da pesquisa intitulada "Gênero e Sexualidade nas redes vivenciadas pelos/as professores/as no cotidiano das escolas", financiada pela Fundação de Amparo a Pesquisa do Estado de Minas Gerais (FAPEMIG) e desenvolvida na Escola Estadual Effie Rolfs, localizada na cidade de Viçosa, Minas Gerais.

A proposta de desenvolvimento do projeto surgiu a partir da prática vivenciada pela orientadora deste trabalho, no momento em que realizava o seu processo de pósdoutoramento na Universidade de Coimbra em Portugal. Nesse período pôde acompanhar o grupo denominado "Centro de Aconselhamento e Orientação de Jovens e regulamentação da Educação Sexual”, integrado na área de educação para a saúde e reconhecido pela Portaria ${ }^{\circ}$ 196-A/2010 no ensino básico e secundário de Portugal. Após retornar às suas obrigações de professora, a pesquisadora se percebeu tocada com a inquietação de verificar a maneira como o debate sobre gênero e sexualidade estava se dando em seu próprio país.

Dito isso, percebemos a necessidade de, por meio de pesquisas, abordar as temáticas referentes ao gênero e sexualidade nas escolas, ao constatarmos que umas das 
principais leis que regem a educação nacional, ou seja, a Lei de Diretrizes e Bases da Educação Nacional, de 1996, não garante o suporte necessário para estas abordagens em sala de aula, assim como em uma escala menor, os cursos de formação continuada, tão importantes para o aprimoramento da prática profissional de educadores/a.

Vale ressaltar que nesse trabalho buscamos acompanhar os fluxos da escola, em suas redes de intensidades, implícitos nas produções dos/das professores/as no que se refere à temática gênero e sexualidade. Posto isso, adentramos ao campo com o intuito de observar aquilo que outrora podia passar despercebido, mas que, todavia, acaba por enriquecer a nossa pesquisa à medida que nossos olhares se tornam atentos, ávidos por questionamentos e situações, tentando captar a sutilidade e o silenciamento das relações de gênero no ambiente escolar. Silenciamento esse que acaba por se tornar um paradoxo, à medida que diante de dois anos de atividades de extensão nas escolas, percebemos que há uma demanda por parte de estudantes e professores/as por atividades relacionadas a gênero e sexualidade, ainda que nossos/as educadores/as afirmem não se sentirem preparados/as para estas discussões.

\subsection{Pesquisa nos/dos/com o cotidiano}

A proposta teórica dos estudos nos/dos/com os cotidianos de Michel Certeau (2008) e fertilizados nas pesquisas de Carlos Eduardo Ferraço (2007, 2008, 2013), Nilda Alves (2001), Inês Barbosa Oliveira (2008), dentre tantos/as outros/as pesquisadores/as da atualidade é a que fundamenta esta pesquisa. Os/as autores/as percebem o cotidiano da escola como um espaço de potências, onde as inventividades ganham força para a criação.

Muitas vezes, no senso comum, tem-se a ideia do cotidiano como algo repetitivo, rotineiro, que segue sempre os mesmos fluxos. Entretanto, o que as pesquisas nos mostram é que os cotidianos não se repetem, mas se reinventam todos os dias com mil maneiras não autorizadas (CERTEAU, 2008), utilizando-se de "narrativas, usos, negociações, traduções e mímicas" (FERRAÇO, 2008, p. 26-27). São trabalhos por meio dos quais se vem buscando superar dicotomias existentes em métodos de pesquisa tradicionais com explicações lineares e causais. Diante disso, talvez seja possível destacar algumas destas dicotomias engessadas em outros métodos de pesquisa, como enfatiza Carlos Eduardo Ferraço (2008): 
[...] as dicotomias sujeito/objeto e teoria/prática; a busca pela objetividade e neutralidade do conhecimento; a ênfase nas quantificações dos processos com vistas a uma dimensão de cientificidade e a análise da realidade pautada em princípios de hierarquia, linearidade, causalidade e classificação, entre outros (p. 26).

Segundo o autor, o cotidiano é "efêmero, incontrolável, caótico e imprevisível" (2007, p.77). Ele foge aos "engessamentos" que se utilizam de categorias e/ou estruturas de análises que, muitas vezes, limitam nossas práticas. Ao chegar ao local de pesquisa com metodologias "a priori” e com roteiro de como devemos proceder, agir, quais teorias utilizar, acabamos não produzindo "com" e/ou "fazendo junto" com aos sujeitos participantes. Para auxiliar na complexidade dos estudos nos/dos/com os cotidianos, Nilda Alves (2001) propõe quatro aspectos de discussão, também validados por Carlos Eduardo Ferraço (2008, p. 29). O primeiro deles seria retirar um pouco da ênfase do sentido da visão, mas sim, mergulhar com todos os sentidos no cotidiano do local de pesquisa a ser explorado; o segundo aspecto é referente à contradição dos métodos de pesquisa das ciências desenvolvidas na modernidade (categorias, teorias, conceitos) métodos estes que, apesar de servirem como base para nossas pesquisas, acabam, muitas vezes, por limitar as produções de tessituras; o terceiro seria a ampliação das fontes e maneiras de lidar com a diversidade encontrada, com a heterogeneidade do ambiente e, por fim, criar uma nova maneira de escrever, que rompa com estruturas tão fixas em outras metodologias de pesquisa, como "novas preocupações, novos problemas, novos fatos" (ALVES, 2001).

Carlos Eduardo Ferraço (2007) apresenta ainda outras importantes observações, definidas por ele como pistas, as quais devemos ficar atentos/as em relação ás abordagens de pesquisa nos/dos/com os cotidianos. Um dos aspectos citados, importantes ao se pensar tais pesquisas, é "considerar a possibilidade de pensar o cotidiano como redes de fazeressaberes tecidas pelos sujeitos cotidianos" (p. 77). Além disso, compreender que as redes fazeressaberes não são uma característica do cotidiano, mas são em si o cotidiano. "As redes não estão no cotidiano. Elas são os cotidianos" (p. 77).

Outra observação pertinente que consideramos importante pontuar é referente às propostas de pesquisas que não tomam como base "a complexidade das redes cotidianas tecidas pelos sujeitos das escolas" (FERRAÇO, ano, p. 78), mas partem de considerações a priori investigando condutas que acabam reforçando dicotomias 
(correto $\mathrm{x}$ errado, bem $\mathrm{x}$ mal), tanto problematizadas pelas pesquisas nos/dos/com os cotidianos:

\begin{abstract}
Por vezes, surgem projetos ou propostas de pesquisas que não tomam como base a complexidade das redes cotidianas tecidas pelos sujeitos das escolas e, mais que isso, trazem as marcas da modernidade expressas, por exemplo, na lógica do bem e do mal, certo ou errado, como nos títulos: "Quais as vantagens e desvantagens..."; "Quais os limites e possibilidades..."; "Que mecanismos facilitam ou dificultam..."; e outros. Há ainda, dentro dessa lógica, sintomas de busca por um procedimento padrão, normativo, ideal, como nos títulos: "Como intervir..."; "Como avaliar..."; "Que procedimentos são necessários...". De modo geral, essas propostas, entre tantas outras, distanciam-se das redes tecidas no cotidiano das escolas e confinam-se em modelos teóricos que têm como pressupostos a busca pelas causas primeiras dos fatos e pela essência das coisas e dos sujeitos, reforçando, quase sempre, naturalizações com relação à escola e, por efeito, à educação (FERRAÇO, 2007, p.79).
\end{abstract}

Nesta perspectiva de pesquisa acabamos, em alguns momentos, nos reconhecendo outrora como estudantes, agora como pesquisadores/as da escola em que nos propomos a mergulhar. Queremos compreender, em meio a tantas possibilidades do cotidiano escolar, justamente as relações de gênero, que tanto nos moldaram e ainda moldam as maneiras com as quais nos vemos, nos sentimos e nos apresentamos para o mundo, produzindo nossas próprias tessituras cotidianas.

\title{
Gênero e Sexualidade na Educação
}

As discussões relacionadas a gênero e sexualidade estão presentes e sempre estiveram em diversos âmbitos da vida social, inseridas no contexto tempo/espaço. As negações, permissões, controles e formas de repressão da sexualidade variam de acordo com o espaço nos quais estão inseridos e o tempo de inserção, sendo que modificando um ou o outro, os valores atribuídos também são alterados. A sexualidade até hoje é encarada por muitos como algo estritamente privado e individual, não cabendo à discussão de maneira ampla e coletiva. Um paradoxo, uma vez que é vastamente divulgada pelas mídias e pouco discutida nos demais espaços formativos, como escola e família (COSTA, 1997; LOURO, 2008).

Enquanto profissionais da educação, convivemos com estudantes que apresentam inúmeras particularidades, e podemos perceber que as feições da sexualidade estão presentes no ambiente escolar em diversos níveis, desde as mais evidentes (como as carícias trocadas) até os aspectos mais sutis (como a formação de 
grupos de amizade, sejam eles exclusivos apenas de meninos, de meninas ou mistos). Com a criação dos Parâmetros Curriculares Nacionais (PCN), em 1997, e a inserção do tema transversal "Orientação Sexual" ocorreu a primeira tentativa de sistematização, em âmbito federal para que os/as professores/as pudessem vivenciar as questões relacionadas a gênero e sexualidade nas escolas brasileiras.

Apesar do destaque dos Parâmetros Curriculares Nacionais referentes a gênero e sexualidade na educação, outras propostas pontuais existiram no Brasil. É possível citar a inserção do estudo da evolução das espécies e da Educação Sexual no currículo do Colégio Batista no Rio de Janeiro em 1930. Mais tarde, entre os anos de 1961 e 1969, a Educação Sexual chegou aos currículos de outros colégios como os Colégios Vocacionais, em São Paulo, o Grupo Escolar Barão do Rio Branco, em Minas Gerais, Colégio Pedro Alcântara, André Maurois, entre outros, no Rio de Janeiro. Em 1970 houve a tentativa da implantação da obrigatoriedade da Educação Sexual nas escolas de todo o país, proposta pela deputada Júlia Steimbruck, porém, que foi vetada pela Comissão Nacional de Moral e Civismo do Ministério da Educação. Já em 1980, as escolas de primeiro e segundo graus de São Paulo introduziram o tema Orientação Sexual no currículo, implementado pela Secretaria Municipal de Educação, sob a orientação do educador e pesquisador Paulo Freire (SPITNEZER, 2005).

A proposta da transversalidade dos temas Ética, Meio Ambiente, Pluralidade Cultural, Saúde, Orientação Sexual, Trabalho e Consumo, e Cidadania é definida pelos Parâmetros Curriculares Nacionais com o objetivo de despertar a cidadania nos/as educandos/as, visto que são assuntos pertinentes em todas as localidades do território brasileiro. Para a escolha dos temas transversais, os critérios de seleção adotados pelo Ministério da Educação e Cultura (BRASIL, 1997) foram: urgência social, com base em "questões graves, que se apresentavam como obstáculos para a concretização da plenitude da cidadania, afrontando a dignidade das pessoas e deteriorando sua qualidade de vida" (p. 25-26); abrangência nacional: temas que fossem pertinentes em todas as localidades do país; possibilidade de ensino e aprendizagem no ensino fundamental: temas passíveis de aprendizagem nos níveis indicados, baseados em experiências já desenvolvidas em ambientes educacionais sobre os temas elencados; favorecer a compreensão da realidade e a participação social: proporcionar que o/a educando/a se posicione perante as questões selecionadas pelos Parâmetros Curriculares Nacionais, intervindo e superando as diferenças, “além de desenvolver um trabalho educativo que possibilite uma participação social dos alunos" (BRASIL, 1997, p. 26). 
Apesar do recomendado pelos Parâmetros Curriculares Nacionais, o trabalho realizado pelos/as professores/as não era garantido. Nesse sentido, como educadores/as de disciplinas como Geografia, História, Física, Química, poderiam fazer esta transversalidade exigida pelo documento? Assim, para o trabalho com gênero e sexualidade, o anseio de abordar este assunto, talvez, não seja diferente dos demais. É necessário muito mais que a recomendação dos Parâmetros Curriculares Nacionais, mas a vontade de criar realidades mais inclusivas para se trabalhar: "É fundamental que esse professor sinta-se ativo nestes projetos, por entender que ele se torna um formador de opinião e inspiração em contato com o seu alunado todos os dias em sala de aula" (NEVES; SILVA, 2015, p. 43).

Partindo desse entendimento, consideramos necessário enfatizar que outras propostas de leis no Brasil não garantem a inserção das discussões de gênero e sexualidade na educação, apenas tangenciam o debate, como pode ser observado em nossa Constituição Federal e nas principais leis que regem a educação no país, como a Lei de Diretrizes e Bases da Educação Nacional - LDB (BRASIL, 1996) e o atual Plano Nacional de Educação - PNE, 2014 - 2024 (BRASIL).

Na Constituição de 1998, no capitulo III da Educação, da Cultura e do Desporto, encontramos uma menção de que todo cidadão possui direito a educação.

Art.205. A educação, direito de todos e dever do Estado e da família, será promovida e incentivada com a colaboração da sociedade, visando ao pleno desenvolvimento da pessoa, seu preparo para o exercício da cidadania e sua qualificação para o trabalho (BRASIL, 1988, p. 01).

Na LDB, no Título II, dos Princípios e Fins da Educação Nacional, no artigo 2 defendem-se as condições de acesso e permanência para todos: "I - igualdade de condições para o acesso e permanência na escola" (BRASIL, 1996, p. 01).

Como mencionamos anteriormente, nos documentos oficiais não temos embasamento legal que discorra a partir das relações sobre gênero na educação, apenas tangenciamentos gerais, como direito a educação para todos, eliminação de todas as formas de discriminação etc. A aceitação da diversidade, universalização e permanência no/do ambiente escolar, respeito às diferenças, eliminação de qualquer forma de discriminação são contemplados no PNE (2014 - 2024), no Art. $2^{\circ}$, nos incisivos I- III e X 
Universalização do atendimento escolar; (...) III - superação das desigualdades educacionais, com ênfase na promoção da cidadania e na erradicação de todas as formas de discriminação (...) X - difusão dos princípios da equidade, do respeito à diversidade e a gestão democrática da educação (BRASIL, 2014, p. 01).

Neste trabalho defendemos que a educação é a medida para amenizar o preconceito, uma vez que um dos principais motivos da intolerância é o desconhecimento e a incompreensão do diferente. Como direito é apresentado que a educação é dever de todos e entendemos que assim seja, independente das particularidades de cada pessoa, sejam elas sexuais ou não.

\section{Aspectos metodológicos da pesquisa}

Esta pesquisa foi desenvolvida tendo como base os estudos nos/dos/com os cotidianos. Desta forma, compreendemos que a realidade não é algo que preexiste aos sujeitos e está lá pronta esperando para ser pesquisada. Diferente disso, ela é construída à medida que é inventada pelos sujeitos, sendo, portanto, múltipla. Neste tipo de pesquisa, mais do que buscar marcas e regras gerais para explicar como temáticas que circunscrevem o gênero e sexualidade, por exemplo, são tratadas nas escolas, o interesse passa a ser o de analisar como as experiências vivenciadas nas escolas são tecidas e reinventadas pelos/com os/as professores/as, juntamente com o pesquisador, e com os/as alunos/as e todos/as que vivenciam esse ambiente. Os significados para a sua formação são múltiplos e subjetivos. Assim, a pesquisa é constituída a partir dos nossos afetamentos das marcas da vida cotidiana, dos acasos, dos imprevistos, das inesperadas situações que constituem a vida da escola, em seus processos de interação, criação e recriações.

Diante disso, segundo Carlos Eduardo Ferraço (2007), devemos compreender que os estudos com os cotidianos acontecem em meio ao que está sendo feito, isto é, em meio "aos processos de tessitura e contaminação das redes" e expressam o "entremeado" das relações dessas redes nos diferentes espaços e tempos vividos pelos sujeitos. Assim, para a realização da pesquisa entendemos que, talvez, o recurso mais importante seja atribuído ao próprio pesquisador que deve se abrir para a experiência4 (LARROSA, 2014), no sentido de 'experienciar' o cotidiano da escola e deixar-se

4 Aqui, entendemos experiência no mesmo sentido que Jorge Larrosa "A experiência é em primeiro lugar um encontro ou uma relação com algo que se experimenta, que se prova. [...] É experiência aquilo que 'nos passa', ou que nos toca, ou que nos acontece, e ao passar-nos nos forma e nos transforma" (2001, p. $25)$. 
afetar pelo mesmo, pois a realidade será construída a partir de seu olhar e das relações que ali estabelecer.

O local escolhido para a realização deste trabalho foi a Escola Estadual Effie Rolfs, que desenvolve o processo educativo junto a aluno/as dos anos finais do Ensino Fundamental e o Ensino Médio completo. Apesar de se localizar em área circunscrita ao centro da cidade, a escola abriga em sua maioria alunos/as de bairros periféricos. A opção por esta comunidade escolar foi a partir do interesse e convite da mesma, uma vez que já haviam sido realizados projetos de extensão em torno da temática gênero e sexualidade, o que colaborou para um bom acolhimento, por parte da direção e professores/as.

O início da pesquisa aconteceu mediante a observação de algumas turmas aleatoriamente, a fim de que se pudessem compreender as composições cotidianas referentes a gênero e sexualidade que se apresentavam. Com o tempo, optamos por nos aproximar mais de uma das turmas do terceiro ano do Ensino Médio. A opção foi feita pela empatia com os/as alunos/as, bem como pela clara demarcação de gênero encontrada: vinte e uma moças e cinco rapazes inseridas/os na classe. Além disso, outra particularidade encontrada foi a de que duas dessas alunas se encontravam grávidas.

\section{Aprofundando o mergulhar: manifestações da sexualidade}

O ambiente escolar é repleto por demonstrações da sexualidade, sejam estas evidenciadas por carícias entre os jovens, por meio de diálogos, músicas, maneiras de se vestir e comportar, frases aleatórias escritas em carteiras e banheiros, dentre outras.

\footnotetext{
Sexualidade é uma dimensão ontológica essencialmente humana, cujas significações e vivências são determinadas pela natureza, pela subjetividade de cada ser humano e, sobretudo, pela cultura, num processo histórico e dialético. A sexualidade não pode, pois, ser restringida à sua dimensão biológica, nem à noção de genitalidade, ou de instinto, ou mesmo de libido. Também não pode ser percebida como uma "parte" do corpo. Ela é, pelo contrário, uma energia vital da subjetividade e da cultura, que deve ser compreendida, em sua totalidade e globalidade, como uma construção social que condicionada pelos diferentes momentos históricos, econômicos, políticos e sociais (FIGUEIRÓ, 1996, p.42).
}

Compreendemos, como disserta a autora, a sexualidade como diversas manifestações em busca do prazer, do carinho e do toque, desvinculando apenas do ato sexual em si, como ocorre no imaginário de grande parte das pessoas. Expressando suas sexualidades, eram perceptíveis as buscas de prazer por meio de carícias entre os casais heterossexuais na escola, que mesmo de maneira discreta, andavam de mãos dadas, se 
abraçavam e trocavam alguns beijos rápidos quando iam se despedir para se direcionarem para as suas salas.

Uma incógnita nesta escola, que acabava desestabilizando os/as presentes, ao expressarem suas sexualidades era a relação de duas alunas. As meninas, ambas de uma mesma sala do segundo ano, andavam de mãos dadas e/ou abraçadas durante o intervalo, assim como na hora da saída da escola. Apesar da proximidade entre as alunas, as mesmas alegavam ser apenas boas amigas. Mesmo não acompanhando a turma em que as alunas estudavam, nos foram relatadas inúmeras situações de preconceito que as envolvia.

Em conversa com alguns rapazes, que se reconheciam como gays, em relação a homossexualidade na escola e preconceito, esses, ao relatarem a situação das meninas, informaram que alguns/as os/as professores/as já haviam solicitado que as separassem de turma ou que ao menos as colocassem em lugares distantes na sala de aula.

Questionamos até que ponto seriam feitas concessões para casais heterossexuais e/ou casais homossexuais no ambiente escolar. Na sala do segundo ano que observávamos, convivíamos com dois casais de namorados heterossexuais. Ambos sentavam um ao lado do outro, demonstravam situações de afeto e carinho, faziam atividades sempre juntos e em momento algum foi relatada qualquer atitude de hostilidade proveniente dos/as professores/as.

\footnotetext{
A heteronormatividade é um sistema pedagógico com resultados sociopolíticos que visa à naturalização da lógica dicotômica dos sexos. Ela é constituída por regras que reproduzem e controlam o sexo dos sujeitos em uma lógica binária, assimétrica e complementar entre mulheres e homens. Para isso, essa lógica precisa ser constantemente reiterada para dar o efeito de substância, de algo natural e de inquestionável (CAETANO, 2012, p.76).
}

Talvez seja possível pensar que, pautada nesta lógica, os/as professores/as, apesar de afirmarem não possuírem preconceitos, são moldados pela heterossexualidade a estranharem todo o tipo de relacionamento que fuja a sua lógica, ocorrência que talvez possa justificar o incômodo direcionado apenas às meninas e não aos outros casais da escola.

Outro fato que também despertou atenção em nossas observações foi referente a uma frase proferida por um dos alunos. Segundo ele, os meninos "deveriam passar o rodo", mas não achava correto tal atitude para as meninas. A expressão passar o rodo diz de uma metáfora correspondente a ficar com várias mulheres, como uma 
"obrigação" da masculinidade, enquanto as meninas deveriam evitar se relacionar com diversos rapazes, pois seriam mal vistas, mal faladas.

$\mathrm{O}$ ato de ficar com várias meninas legitima a masculinidade do garoto, que tem seus "comportamentos masculinos vigiados, avaliados e julgados o tempo todo, de modo intensivo e extensivo, em termos de sua relação com a sexualidade" (SALES; PARAÍSO, 2013, p. 613). O corpo masculino é altamente visado, e quaisquer atividades que fujam do padrão sexual esperado do homem é apontado. Os rapazes são “zoados" quando fogem a esta padronização. Atos como cochichar, rebolar, ficar de agarração entre si e não gostar de futebol é apontado como desvio (SALES; PARAISO; 2006). Já, para as meninas, outros valores são colocados em pauta:

\footnotetext{
A questão colocada à moça é saber se posicionar de modo a ser atraente e sedutora, mas jamais ceder a todas as investidas masculinas, nem tampouco ser a protagonista desse investimento, quando este for classificado como excessivo. A garota deve ser difícil (SALES; PARAİSO, 2006, p. 617).
}

Percebemos que esta normalização de corpos e parceiros, as expectativas de quantos e com quem se relacionar é legitimada no ambiente escolar, tanto pelos/as estudantes quanto pelos/as próprios/as funcionários/as da escola. As convenções e representações sociais aqui discutidas não ficam restritas do lado de fora das escolas, e no ambiente que se era para deslegitimar estes paradigmas, a reprodução ocorre quase que majoritariamente, reproduzida pelo corpo discente e docente.

\section{Representatividade e Orientação Sexual na escola}

Nos últimos anos, vimos uma crescente onda de divulgação LGBTTTQI+5 no cotidiano e nas mídias, seja representada pelo aumento e visibilidade das Paradas LGBTTTQI+, pela inserção de personagens homossexuais em novelas e/ou séries, por canais no Youtube6 direcionados a este público, como pela influência de personalidades LGBTTTQI+, como a drag queen brasileira Pabllo Vittar e a americana RuPaul, pelas mídias sociais, etc.

5 Utilizamos LGBTTTQI+ a fim de considerar os sujeitos que se reconhecem como lésbicas, gays, bissexuais, transexuais, travestis, transgêneros, não-binários e intersexuais.

6 Youtube é uma plataforma que busca o compartilhamento de vídeos criada em Fevereiro de 2005. 
Ressaltamos alguns fatores que possivelmente tenham contribuído para a construção desta identidade LGBTTTQI+, que vem se acentuando continuamente desde o final da década 1970:

\begin{abstract}
Destacam-se os momentos: o período da ditadura à abertura política; o impacto da pandemia do HIV/AIDS; a transição da perspectiva patologizante para uma de direitos no âmbito dos novos movimentos sociais; o processo de construção de um circuito de entretenimento gay nas cidades brasileiras; a evidência do evento da Parada Gay; o emergente movimento LGBTIQ+; e a atuação progressista do judiciário pelo reconhecimento aos direitos sociais e civis como valores universais presentes na Constituição Federal além de legislações consolidadas em muitos Estados Brasileiros em suas Leis Orgânicas (MOTA, 2012, p. 219).
\end{abstract}

Fatos como estes proporcionaram uma maior aceitação em prol da diversidade, juntamente com grupos de apoio e resistência, influência para que os LGBTTTQI+ assumam-se cada vez mais cedo e reconheçam suas sexualidades como uma das maneiras de se expressar. Em se tratando do ambiente pesquisado, todos os quatro homossexuais da sala que acompanhamos, entre 16 e 18 anos, já evidenciavam sua sexualidade no ambiente escolar, reafirmando seus direitos e exigindo o mesmo tipo de tratamento que os demais. Em conversa com um destes estudantes, nos foi revelado que quando ocorre algum tipo de discriminação no ambiente escolar eles se juntam para ajudar uns aos outros, demonstrando como o apoio dos iguais é fundamental neste processo. Nesta instituição, percebemos que a discussão sobre gênero e sexualidade é uma demanda muito mais trazida pelos/as próprios/as educandos/as, do que dos/as professores/as da escola. Das disciplinas acompanhadas (Matemática, Geografia e em menor quantidade, Português), não percebemos qualquer tentativa dos/as professores/as em realizar o debate sobre gênero e sexualidade no ambiente escolar. Vale ressaltar que a escolha destas disciplinas não foi proposital, mas sim devido a possibilidade de participação destes horários com as autoras e o autor do artigo e os/as professores/as que concordaram com a observação de suas aulas

Defendemos, com base nos Parâmetros Curriculares Nacionais (1996), que independente da disciplina, os momentos em sala de aula com piadinhas, situações de preconceito e/ou questionamentos referentes a sexualidade são propícios para debate sobre gênero e sexualidade no ambiente escolar, mesmo que não seja a temática principal da aula. $\mathrm{O}$ documento aponta que gênero e sexualidade deve ser trabalhado por meio da transversalidade, já que os assuntos são possíveis de discussão em todas as disciplinas, não só apenas em Ciências/Biologia e Educação Física, como acredita- se no senso comum. Grande parte das abordagens sobre sexualidade acaba sendo realizada 
com o viés higienista e biológico. "Falar de sexualidade não significa falar só de doenças, riscos e perigos. Sexualidade é, antes de tudo, prazer, afeto, relação. Mais que isso falar de sexualidade é falar de direito" (BORTOLINI, 2008, p. 85).

Nesse sentido, o/a professor/a que tiver interesse em debater estas discussões no ambiente escolar não precisa escolher uma aula específica para falar sobre. Nossas próprias observações do cotidiano da escola mostram que pequenas observações em seus locais de trabalho, em contato com os/as alunos/as, podem despertar as mais diversas possibilidades e questionamentos.

De acordo com Maria José Garcia Werebe (1981), o trabalho com orientação sexual no ambiente escolar pode ser concebido de duas maneiras: formal e informal. A formal seria aquela sistematizada, onde existiria uma programação fixa para se trabalhar com sexualidade nas escolas; a informal seria aquela em que não precisaria de um sistema prévio de abordagem, cada professor/a poderia intervir para se trabalhar com sexualidade esporadicamente.

Apesar de não ter sido observado o debate acerca da temática gênero e sexualidade nas aulas dos docentes, nem transversal aos assuntos principais e nem como objetivo principal, os próprios alunos protagonizam o debate, seja por meio de trabalhos em grupos sobre o assunto, fazendo oficinas na escola sobre a temática, se organizando e defendendo a expressão de sua sexualidade como uma variável tão legítima como a heterossexual.

Um destes momentos de protagonismo dos estudantes foi observado quando em um trabalho de Sociologia de tema livre, um dos alunos optou por apresentar sobre Orientação Sexual e Identidade de Gênero. Esta demanda foi levantada pelo próprio estudante, que apresentou e discutiu a temática na sala por meio de cartazes. Mesmo não podendo estar presentes neste dia, tivemos contato com material elaborado e o estudante apontou as motivações que o levou a tal escolha: ser gay, negro e consciente do seu direito de se apresentar e ser reconhecido como tal pela comunidade.

\section{Considerações}

Tecer considerações finais da pesquisa pode ser o caminho mais difícil até aqui percorrido. Nossas observações em campo não nos garantiram respostas exatas, todavia, reafirmaram algumas hipóteses levantadas antes da inserção na escola. Como exemplo podemos citar a importância da formação continuada na prática docente para o 
desenvolvimento destas atividades, uma vez que os docentes alegaram não sentirem-se preparados para tais abordagens. Outra confirmação foi referente ao protagonismo dos/as estudantes em apresentarem sua sexualidade e se organizarem para exigir direitos e respeito como os demais alunos da escola. Mesmo com políticas objetivando o silenciamento dos/as professores/as

No cotidiano escolar, percebemos que a sexualidade dos/das alunos/as é extremamente evidente, e por mais que os/as educadores/as, por muitas vezes, fechem os olhos, ela está ali, pulsando, sendo demonstrada para todos os lados, desde maneiras mais sutis até as mais evidentes possíveis.

Das aulas observadas, poucos foram os momentos propícios para um debate sobre gênero e sexualidade, o que talvez, possa ter sido influenciado pelas matérias que acompanhamos (Geografia e Matemática)7, além dos assuntos que estavam sendo trabalhados pelos/as professores/as. Tal fato nos chama a atenção, uma vez que acreditamos na possibilidade de trabalhar gênero e sexualidade independentemente do momento específico para tal. Utilizar outras aulas e disciplinas para discutir a temática nos parece pertinente, já que enquanto construções sociais, tanto o gênero como a sexualidade se fazem presentes em todos os momentos. Assim sendo, é de extrema importância levar este debate para o ambiente escolar, seja por meio de palestras e intervenções artísticas com os/as estudantes, e também como modos para a formação continuada de professores/as.

Como mostrado na pesquisa, os aspectos legais que regem a educação no Brasil não embasam as discussões sobre gênero e sexualidade. A Base Nacional Curricular Comum, aprovada em 2017 para a Educação Infantil e Ensino Fundamental e em 2018 para o Ensino Médio, exclui todas as menções referentes a gênero, e limita os aspectos da sexualidade apenas ao viés biológico e reprodutivo, tal como a prevenção de Infecções Sexualmente Transmissíveis. Podemos encontrar, porém, alguns artigos que tangenciam o debate, como os citados na Constituição Brasileira (1988), na Lei de Diretrizes e Bases (1996) e no Plano Nacional de Educação (2014-2014). O maior suporte legal que possibilita estas discussões no país em nível nacional com mais de vinte anos de elaboração, ainda são os Parâmetros Curriculares Nacionais (1998) com o tema transversal "Orientação Sexual". 
Sabendo da temática da pesquisa, os/as professores/as participantes alegavam não ter preconceitos e respeitarem todos/as os/as alunos/as, independente de suas particularidades. Todavia, estas afirmações não se aproximavam das observações realizadas pelos/as alunos/as referente tanto aos relacionamentos heterossexuais, bem como á relação das alunas que, mesmo afirmando serem apenas amigas, acabam por gerar certo incômodo nesse espaço.

No geral, o debate sobre gênero e sexualidade só ocorreu na escola pesquisada mediante uma demanda sugerida pelos/as próprios/as alunos/as, que proporcionaram oficinas, debateram o tema nas apresentações de trabalho e/ou afirmam sua sexualidade para os demais. Por fim, consideramos que estas são apenas considerações iniciais, uma vez que o que foi apreendido aqui não se finalizará com o fim desta produção, mas começará um novo ciclo, para novas descobertas e novas tessituras cotidianas.

\section{Referências}

ALVES, Nilda. Decifrando o pergaminho - o cotidiano das escolas nas lógicas das redes cotidianas. In : OLIVEIRA, Inês Barbosa de, ALVES, Nilda (Orgs). Pesquisa no/do cotidiano das escolas- sobre redes de saberes. Rio de Janeiro: DP\&A, p. 13-38.

BRASIL. Secretaria de Educação Fundamental. Parâmetros curriculares nacionais: terceiro e quartos ciclos: apresentação dos temas transversais. Secretaria de Educação Fundamental. Brasília: MEC/SEF, 1997.

BRASIL. Constituição da República Federativa do Brasil. Brasília, DF: Senado Federal: Centro Gráfico, 1988. Disponível em:< https://www2.senado.leg.br/bdsf/bitstream/handle/id/518231/CF88_Livro_EC91_2016. pdf $>$. Acesso em: 26 de Abril de 2019.

BRASIL, Lei de Diretrizes e Bases. Lei no 9.394/96, de 20 de dezembro de 1996. Disponível em: http://www2.senado.leg.br/bdsf/bitstream/handle/id/529732/lei_de_diretrizes_e_bases_ 1ed.pdf > .Acesso em: 26 de Abril de 2019.

BRASIL. Plano Nacional de Educação - PNE/Ministério da Educação. Brasília, DF: INEP, 2011.

BORTOLINI, Alexandre. Diversidade sexual na escola. Pró-reitoria de extensão/UFRJ, Rio de janeiro: 2008.

CERTEAU, Michel de. A invenção do cotidiano: 1. Artes de fazer/ Michel de Certeau; 15. ed. Tradução de Ephraim Ferreira Alves. Petrópolis, RJ: Vozes, 2008.

COSTA, M. Sexualidade na adolescência: dilemas e crescimentos. 9. ed. L\&PM, 1997. 
DELEUZE. G. Mil platôs: capitalismo e esquizofrenia. v. 5. São Paulo: 1998.

FERRAÇO, Carlos Eduardo. Pesquisa com o Cotidiano. In. Educação e Sociedade. Campinas, vol. 28, n.98, p.73-95, jan./abr. 2007. Disponível em:

<http://www.cedes.unicamp.br>. Acesso em: 15 de outubro de 2018.

Currículo, formação continuada de professores e cotidiano escolar: fragmentos de complexidade das redes vividas. In: FERRAÇO, Carlos Eduardo (Org.). Cotidiano escolar, formação de professores (as) e currículo. $2^{\mathrm{a}}$ ed. São Paulo: Cortez, 2008. p.1542.

Carlos Eduardo; NUNES, Kêzia Rodrigues. Currículos, culturas e cotidianos escolares: afirmando a complexidade e a diferença nas redes de conhecimentos dos sujeitos praticantes. In: FERRAÇO, Carlos Eduardo; CARVALHO, Janete Magalhães (Orgs.). Currículos, pesquisas, conhecimentos e produção de subjetividades. Petrópolis, RJ: Nupec/Ufes, 2013. p. 71-104.

FIGUEIRÓ, Mary Neide Damico. Formação em educadores sexuais: adiar não é mais possível. Campinas, SP: Mercado de Letras; Londrina: Paraná, PR : Eduel, 2006.

LARROSA, Jorge. Tremores: escritos sobre experiência. ANTUNES, C; GERALDI, J. W. (Trad.). Belo Horizonte: Autêntica Editora, 2014.

LOURO, G. L. Gênero, sexualidade e educação: uma perspectiva pós-estruturalista. Ed. Petrópolis, RJ: Vozes, 2008.

MOTA, Murilo Peixoto da. A construção da homossexualidade no curso da vida a partir da lembrança de gays velhos. Disponível em:<

http://www.cchla.ufrn.br/bagoas/v06n07art10_mota.pdf>. Acesso em: 26 de Abril de 2019.

NEVES, André Luiz Machado das; SILVA, Iolete Ribeiro da. Diversidade Sexual e protagonismo de professores: uma análise sócio-histórica dos significados. Manaus/São Paulo (SP): Fapeam/Martinari, 2015.

OLIVEIRA, Inês Barbosa de. Certeau e as artes de fazer: as noções de uso, tática e trajetória na pesquisa em educação. In: OLIVEIRA, Inês Barbosa de; ALVES, Nilda (Org.). Pesquisa nos/dos/com os cotidianos das escolas - sobre redes de saberes. Petrópolis: DP et. ali, 2008, p. 49-64.

ROLNIK, Suely. Cartografia sentimental: transformações contemporâneas do desejo. São Paulo: Estação Liberdade, 2011.

SALES, Shirlei, PARAÍSO, Marlucy. O Jovem Macho e a Jovem Difícil: governo da sexualidade no currículo. Educação \& Realidade, Porto Alegre: v. 38, n. 2, p. 603-625, abr./jun. 2013.

SPITNEZER, Regina Henriqueta Lago. Sexualidade e adolescência: reflexões acerca da educação sexual na escola. 2005. Dissertação (Mestrado em Educação) -

Departamento de Educação, Universidade Estadual de Maringá, Maringá, PR, 2005. 
Disponível em:< http://livros01.livrosgratis.com.br/cp070540.pdf >. Acesso em: 20 de Maio de 2019.

WEREBE, Maria José Garcia. A implantação da educação sexual no Brasil. Cadernos de pesquisa, n²6. Fundação Carlos Chagas, 1977.

Recebido em maio de 2019.

Aprovado em agosto de 2019. 